\title{
Enhancement of motivational efficiencies of adolescents through yoga and science of living
}

\author{
Vivek Maheshwari' ${ }^{1}$, J.P.N. Mishra, ${ }^{2, *}$, Alok Pandey ${ }^{3}$ \\ ${ }^{\mathbf{1}}$ Assistant Professor, Dept. of Yoga \& Science of Living, Jain Vishva Bharati Institute, Ladnun, Rajasthan, ${ }^{\mathbf{2}}$ Professor and Dean, \\ ${ }^{3}$ Yoga Instructor, ${ }^{2,3}$ Central University of Gujarat, Gandhinagar, Gujarat, India \\ *Corresponding Author: \\ Email: jpnmishra@gmail.com
}

\begin{abstract}
Introduction: Adolescent's behavior consists of all their physical response, habits, skills; all their organic responses, feelings, emotions, and tensions; all their intellectual responses, perceiving, thinking, and reasoning. These responses are found in the field of motives, which are mainsprings of their behavior.

Objective: To develop a module of Science of Living training for promoting motivational efficiency of adolescent students.

Methodology: Keeping in view the nature and objectives of this study, out of 100 registrants, 60 boys and girls with the age range of 12 to 17 years were chosen for the study based on the inclusion and exclusion criteria. Random sampling was used for the selection of the participants and all the subjects were from similar educational and socio-economic status. A randomized prepost study research design was used for the study. The participants received a combined approach of Yoga and Science of Living (SOL) activities of 45 min, 5 days per week, for 3-months. Multidimensional motivation test constructed by Dr. Roma Pal was used as a tool for assessing motivational efficiency of the subject, first at the onset of the study and after three months of Yoga and Science of Living intervention module.

Result: it was evident that Yoga and SOL practice leads to a significant improvement in motivational efficiency of the adolescent practitioner student. The findings of the study indicate that there is a significant difference between the constituent variables of motivational efficiency before and after the practice of Yoga and Science of Living.

Summary: It implies that Yoga and SOL practice is useful in the enhancement of Psycho-physiological well-being, improvement in confidence, coping, transcendence, inadequate mental mastery of the practitioner. Thus, it was inferred from the findings that the hypothesis assumed before the start of the study has been amply proved.
\end{abstract}

Keywords: Science of Living (SOL), Yoga, Motivation, Perception, Adolescent, Thinking and reasoning.

\section{Introduction}

An infant's early behavior is determined by basic biological needs - a child cries when hungry, cold or in pain. But as the child grows and reaches on the adolescents age, new motives appear that are leavened by interacting with other persons. Maslow (1970) proposed a motivation hierarchy - physiological, safety, belongingness and love, esteem, cognitive, aesthetic and self - actualization motives. Obviously motivations determine our actions; conversely our behavior and behavior makes our personality. So our personality is the reflection of our inner stream. Freud (1940) also said that our actions are determined by inner forces and impulses or motivations. It is possible to alter motivational efficiency by changing one's cognitions.

Adolescent's behavior consists of all their physical response, habits, skills; all their organic responses, feelings, emotions and tensions; all their intellectual responses, perceiving, thinking and reasoning. These responses are found in the field of motives, which are mainsprings of their behavior (Srivastava, 2008).

A number of studies have investigated that yoga; meditation and pattern of life style are the way of changing people's cognitions. The motivational efficiencies are closely related to healthy body and healthy mind. Motivation is a internal energy which farce human behavior to words goal. Man has a big pool of positive and negative energy. Every adolescent wants to enhance and renovate his motivational efficiency. Typically, almost everyone has the mindset for personal and progressive behavior modification. But the question is how to motivate our self and how to transform our personality? These are significant questions? Regarding motivational efficiency and transformation, Acharya Mahapragya (1995) emphasized the importance of Science of Living paradigm.

Preksha Meditation is experimental methodology of Science of Living. Science of living is a science which studies the fundamentals of living, techniques for personality development their application in different spheres of life ultimately to bring about the development of a balanced and integral personality. Acharya Mahapragya (1995) enlightened following various aspects of Science of Living (SOL):

1. SOl is training in the science and art of living a proper life.

2. SOl is the name of the education of non-violence, education of morality and education of internal transformation.

3. The name of the associated system of Anuvrat, Preksha Meditation in education is SOL.

4. The name of the search for the rules of life is SOL. This way, SOL is a teaching of education. It is based upon spiritual wisdom, philosophy of life, Indian Yoga System and, skills of Preksha Meditation. Its aims 
is to help an individual so that he can live a balanced and healthy life with full of values. By the training of SOL every student at awakens his own dormant consciousness and capabilities, pushing away obstacles in achieving his goal, can live a balanced healthy and well organized life. Science of Living is the synthesis of the ancient wisdom and the modern scientific Knowledge for developing an integrated personality through attitudinal charge and behavior modification. It is a positive resolve for creating a healthy human society - healthy in all respects- physically, mentally and emotionally.

The widest application of the SOL is in the field of education, both formal and informal. It is obvious that the main purpose of education should be character development, mental equilibrium and peace of mind. Alas this purpose has been entirely ignored by the educationists. The present system of education does possess elements which are efficient enough to develop the intellect and talent potential but in spite of becoming an expert in one's respective field of education, one does suffer from enormous mental tension, because he has not been taught how to relax and how to enhance motivational efficiencies. It is abundantly clear that we shall have to supplement and enrich the present system with such training that can reinforce the student's reasoning mind, increase his capacity for bearing stress instead of bucking down and help him to subdue fear, hatred, jealousy and lust. With these facts in the methodology of SOL we envisaged to test its efficiency in the development of motivational efficiency in the students

\section{Objective}

To develop a module of Science of Living training for promoting motivational efficiency of adolescent students.

Hypothesis: We hypothesized that the training Science of Living will improve the motivational efficiency of the adolescent, students.

\section{Research Methodology}

Participants: Keeping in view the nature and objectives of this study, out of 100 registrants, 60 boys and girls with the age range of 12 to 17 years from Vimal Vidhya Vihar Senior Secondary School, Ladnun (Rajasthan) were chosen for the study based on the inclusion and exclusion criteria. Random sampling was used for the selection of the participants and all the subjects were from similar educational and socioeconomic status. The study was conducted between July 15, 2016 and October 15, 2016.

Research Design: It was a randomized pre-post study. After the initial process of screening, participants were randomized by researcher using lottery method of randomization. Every subject served as its own control. No control group was contemplated.

Intervention: The adolescent participants received a combined approach of Yoga and Science of Living (SOL) activities of $45 \mathrm{~min}, 5$ days per week, for 3months. The intervention module of Yoga and SOL program was conducted by certified Preksha Meditation teachers from Department of Science of Living, Jain Vishva Bharati Institute, Ladnun. The details of the intervention (Yoga and SOL program) were as follows: Mahapran Dhwani - 5 min.

Joint Movement Exercises - 5 min.

Sun Salutation -20 min

Swas Preksha - 10 min

Perception of Psychic Colour -5 min

Assessment Tools: Multidimensional motivation test constructed by Dr. Roma Pal was used as a tool for assessing motivational efficiency of the subject, first at the onset of the study and after three months of Yoga and Science of Living intervention module. This psychological test includes 54 items. Each item was to be answered in 'very good', 'good', 'average', 'not good' and 'not quite well'.

\section{Result}

Table 1: Comparison of motivational efficiency at different phases

\begin{tabular}{|l|c|c|c|c|c|}
\hline \multicolumn{1}{|c|}{ Schedule of observation } & Mean & SD & Correlation & SEd & t-value \\
\cline { 1 - 5 } Pre test & 193.43 & 17.280 & 0.74 & 3.204 & $5.337^{*}$ \\
\cline { 1 - 4 } Post test & 210.53 & 16.296 & & & \\
\hline
\end{tabular}

$\mathrm{df}=59 ; *=$ Significant at 0.01 level

The perusal of Table 1 reveals that the mean value of pretest was 193.43 and the same of the Post test was 210.53 bearing ' $t$ ' value of 5.337. The ' $t$ ' value is significant at 0.01 . From the findings it was clearly evident that Yoga and SOL practice leads to a significant improvement in motivational efficiency of the adolescent practitioner, student.

\section{Discussion}

The present study was intended to study the effect of three months of Yoga and Science of Living practice on motivational efficiency in adolescents. The results obtained were highly significant and indicates that Yoga and Science of Living play a vital role in keeping the motivational efficiency. The result is in agreement with the findings reported by Burke (2009); Harnett and Dawe (2012); Miners (2008) who also reported improvement in wellbeing, reduce worries, anxiety, distress, reactivity and bad behavior, improve sleep, self-esteem, and bring about greater calmness, relaxation, and self-regulation and awareness as result of practice of Yoga. Gelderloos et al. (1990) suggested that meditation practice yield enhanced confidence 
level and a sense of control empathy and selfactualization. Several investigators conclude that the practice of meditation improves cognitive task performance.

Earlier findings of studies on Yoga and Meditation were aligned with the present study in cognitive and performance skills in the young. Saltzman and Goldin (2008) carried out an assessment of 8--week Meditation intervention with 31 children, aged 9 to 11 . The result analysis indicated feasibility, and improvements for children in attention, emotional reactivity and some areas of meta--cognition, based on self and parent report measures, and objective measures of attention and cognitive performance. Zylowska (2008) reported the results of a pilot study of 8 adolescents with ADHD who took part in a mindfulness meditation course and showed improvements on tasks measuring attention and cognitive inhibition, and in externally observed and self-reported anxiety and depressive symptoms.

Yoga is a way of life and the Science of Living is a training course based on scientific principles. It comprises both practice training and theoretical studies. In this research, researcher included the practical training module. Joint movement exercises strengthened all muscles, limbs and other external organs. Mahapran Dhwani creats vibration in brain and probably removes any kind of obstruction in brain blood supply thus increasing the operative efficiency of the brain. Surya Namaskar gives exercise to deep seated organs, control their activity and improve work efficiency. By Swas Preksha, we control our breathing consciously and regulation of breath results in determination and increase of will power and control on the autonomic nervous system. Preception of psychic colour with visualization of yellow colour on Gyan Kendra on the top of the head probably helps regulate in the secretion of Pituitary and Pineal gland. Thus the practice of Yoga and Science of Living results bodily development, intellectual development, mental development and emotional development. These all dimensions of development lead motivational efficiency.

Kumar (1991) reported that the Science of Living educates the mind, the speech and the body alive. Educating the body means developing the competence to sit in the same posture for a prolonged period. Educating the speech means not having any propensity to speak even though there may be many compulsive inner urges to do so. Similarly educating the mind means being free from unbridled memory, imagination and thinking. Today the biggest problem is that students have lost faith in their power. Practice of Science of Living yields the following three achievements:

1. Awareness of one's power.

2. Access to those paths of development which the above awareness makes known.
3. Careful study practice and experimentation. Ones these achievements have been made, faith and selfconfidence are automatically built.

The findings of the study thus indicate that there is a significant difference between the constituent variables of motivational efficiency before and after the practice of yoga and Science of Living. It implies that Yoga and SOL practice is useful in the enhancement of Psycho-physiological well-being, improvement in confidence, coping, transcendence, inadequate mental mastery of the practitioner. Thus, it was inferred from the findings that the hypothesis assumed before the start of the study has been amply proved. The facts and figures as stated in the foregoing paragraphs and the Table 1 above supports the hypothesis that the training of Science of Living which also includes practice of selected components of Yoga does lead to a significant improvement in, and consequently an enhancement of, motivational efficiency of the adolescents.

\section{References}

1. Acharya Mahapragya (1995). Preksha Dhyana: Therapeutic Thinking ( $3^{\text {rd }}$ ed.). Ladnun: Jain Vishva Bharati.

2. Burke, C.A. (2009) Mindfulness--based approaches with children and adolescents: a preliminary review of current research in an emergent field, Retrieved 23 December 2009 from Journal of Child and Family Studies, http://www.springerlink.com/content/e1638088141n327 $\mathrm{m}$

3. Freud, S. (1940). Outline of Psychoanalysis (standard ed.). vol. XXIII. London: Hogarth Press.

4. Gelderloos P, Hermans HG, Ablserom HH and Jacoby R. (1990). Transcendence and Psychological Health: Studies with Long Term Participants of the Transcendental Meditation and TM- sidhi Program. Journal of Psyc hology 1990;124(2);177-97.

5. Gopukumar, K., \& Hussain Ali, M. (2002). Meditation A harbinger of subjective well-being. Journal of Personality and Clinical Studies. 19, 93-102.

6. Harnett, P.S. and Dawe, S. (2012) Review: The contribution of mindfulness--based therapies for children and families and proposed conceptual integration. Child and Adolescent Mental Health (accepted for publication).

7. Kumar Mahendra (1991). Science of Living (1sted.). Ladnun: Jain Vishva Bharati.

8. Maslow, A.H. (1970). Motivation and Personality (2nded.). N.Y.: Harper and Row.

9. Miners, R. (2008) Collected and Connected: Mindfulness and the early Adolescent. Dissertations Abstract International: Section B. The Sciences and Engineering, 68,9 .

10. Saltzman, A., \& Goldin, P. (2008). Mindfulness based stress reduction for school--age children. In S. C. Hayes \& L. A. Greco (Eds.), Acceptance and mindfulness interventions for children adolescents and families (pp. 139-161). Oakland, CA: Context Press/New Harbinger.

11. Srivastava, M. (2009). Psychology in Physiotherapy Practice (1sted.). Delhi: Ahuja Publishing House.

12. Zylowska, L. (2008) Mindfulness meditation training in adults and adolescents with ADHD: A feasibility study. Journal of Attention Disorders 2008;11 (6) 737-746. 